\title{
Neonatal Endotoxin Exposure Influences HPA Responsivity and Impairs Tumor Immunity in Fischer 344 Rats in Adulthood
}

\author{
DEBORAH M. HODGSON, BRENDON KNOTT, AND FREDERICK R. WALKER \\ Laboratory of Neuroimmunology, School of Behavioural Sciences, The University of Newcastle, \\ Callaghan, New South Wales, 2308, Australia [D.M.H., B.K., F.R.W.]
}

\begin{abstract}
ABST
Recent research in rodents has demonstrated that exposure to
bacterial endotoxin during the neonatal period alters the devel-
opment of the hypothalamic-pituitary-adrenal axis resulting in
hypersecretion of corticosterone after stress-exposure in adult-
hood. Given the known interactions between glucocorticoids and
the immune system it was hypothesized that such alterations may
impact on immune outcomes. Fischer 344 rats were treated with
endotoxin $(50 \mu \mathrm{g} / \mathrm{kg}$ Salmonella enteritidis, i.p.) or the vehicle
on postpartum $\mathrm{d} 1,3,5$, and 7 . In adulthood, animals were
subjected to chronic stress $(6 \times 10 \mathrm{~h} / \mathrm{d}$ restraint stress), and the
effect on resistance to tumor colonization (experiment 1$)$ and
natural killer cell activity (experiment 2$)$ was assessed. Experi-
ment 3 assessed corticosterone responses to acute stress in
adulthood after neonatal endotoxin or saline treatment. Neonatal
endotoxin exposure resulted in a 2-fold increase in tumor colo-
nization ( $p<0.001)$ and a significant impairment in the activity
of natural killer cells $(p<0.01)$, cells critically involved in the
\end{abstract}
Development of the fetus is determined by interactions between, among others, the neurochemical, immune, and endocrine systems. Cell-mediated and humoral immunity continue to develop throughout the early postnatal period and are dependent on appropriate immune-endocrine signaling $(1,2)$, and normal development of the HPA and hypothalamicgonadal axes is influenced by early immune activation $(3,4)$. Exposure to stress during this postnatal period influences stress responsivity in adulthood. For instance, exposure of neonatal rat pups to bacterial endotoxin, or separation of pups from their dam, results in hyperresponsivity of the HPA axis to stress when these animals, as adults, are exposed to stress (5-9). There is a common hypothesis concerning the mechanism behind these long-term changes, that exposure of the neonate to stress, at a period when there is considerable neural plasticity, alters glucocorticoid receptor numbers producing changes

Received March 22, 2001; accepted August 8, 2001.

Correspondence and reprint requests: Deborah M. Hodgson, Ph.D., School of Behavioural Sciences, Laboratory of Neuroimmunology, University of Newcastle, Callaghan, 2308, New South Wales, Australia; e-mail: dhodgson@psychology.newcastle.edu.au

Supported by RMC grant No. 2821078 from The University of Newcastle, Australia. surveillance and eradication of tumor cells. Neonatal endotoxin exposure also resulted in a significant decrease in gain weight that persisted into adulthood ( $p<0.05$ ), and potentiation of corticosterone responses to acute stress in adulthood $(p<0.05)$. We conclude that neonatal endotoxin exposure produces longterm changes in the hypothalamic-pituitary-adrenal axis, and has significant long-term effects on immune function, specifically in terms of resistance to tumor colonization in adulthood. (Pediatr Res 50: 750-755, 2001)

Abbreviations
CBG, corticosteroid-binding globulin
E:T, effector to target
HPA, hypothalamic-pituitary-adrenal
LPS, lipopolysaccharide
NK, natural killer

in HPA sensitivity $(6,10,11)$. Consistent with this hypothesis, both neonatal endotoxin exposure and maternal separation induce high levels of ACTH and corticosterone in neonatal rodent pups (12-14). This is associated with reduced glucocorticoid receptor density in the hypothalamus, hippocampus, and frontal cortex (5), increased hypothalamic corticotropinreleasing hormone mRNA levels (6), and increased plasma corticosterone levels $(6,7,9)$ in adulthood. This downregulation in receptor concentration results in reduced glucocorticoid negative feedback sensitivity and, consequently, more-pronounced and longer-lasting elevations in corticosterone after stress exposure in adulthood (7).

Altering the responsivity of the HPA axis has potentially important implications given that glucocorticoids are major immunoregulatory factors (15). Glucocorticoids alter leukocyte trafficking and enumeration (16), retard cell growth and differentiation (17), and depress the activity of NK cells (17), cells critically involved in the early surveillance and eradication of tumorigenic cells. Given that neonatal exposure to endotoxin is associated with hypersecretion of glucocorticoids, it would appear likely that this could have an impact on 
immunologic functioning and disease resistance in later life. In support of this proposal, neonatal endotoxin exposure has been shown to potentiate stress-induced suppression of cell proliferation and to reduce sensitivity to adjuvant-induced arthritis in the rat (9).

Building on this research this study investigated the possibility that neonatal exposure to bacterial endotoxin may impact on tumor immunity, altering susceptibility to tumor growth in adulthood. This study investigated the effect of neonatal endotoxin exposure, in Fischer 344 (F344) rats, on resistance to tumor colonization and growth (experiments $1 \mathrm{~A}$ and 1B), NK cell activity (experiment 2 ), and HPA reactivity (experiment 3 ) when these rats were exposed to stress in adulthood. Tumor resistance was investigated using a mammary adenocarcinoma cell line, MADB106, which is syngeneic to the F344 rat. MADB106 tumor cells metastasize only to the lungs after i.v. inoculation (18), and pulmonary retention of these tumor cells, and the subsequent growth of lung metastases, is tightly regulated by NK cell activity $(18,19)$. Colonization of MADB106 tumor cells has been shown to be highly sensitive to the effects of stress exposure (20-22).

We report that exposure of rat pups to bacterial endotoxin in the early postnatal period decreased resistance to tumor growth and depressed the activity of NK cells when these animals reached adulthood. Neonatal endotoxin exposure also potentiated corticosterone responses to acute stress and produced a decrement in weight gain that persisted from birth into adulthood.

\section{METHODS}

Subjects. Pups were bred from naive, 8-wk-old F344 rats obtained from the Animal Resource Center (Perth, Western Australia). After successful mating, dams were housed individually, and cages were checked daily until the birth of litters. The day of birth was designated d 0 , and dams and pups were left undisturbed on this day. At all times during the experiment, except those noted below, rats had food and water available $a d$ libitum and were maintained on a 12-h light-dark cycle. The light phase began at $0600 \mathrm{~h}$, and the temperature was maintained at $20 \pm 2^{\circ} \mathrm{C}$. On birth litters were randomly allocated to either saline or endotoxin treatment groups. Only litters containing 6-10 pups were used. All litters were weaned on d 22, and remained group housed as litters until d 36 , at which point female pups were culled, and remaining males were housed individually. Female pups were not used in this study because of the difficulty in controlling for estrus cycle, a factor that has previously been shown to influence tumor metastasis (23).

Neonatal drug administration. In each experiment neonatal pups were treated with endotoxin or saline solution on postpartum d 1, 3, 5, and 7. Neonates were injected i.p., using a Hamilton syringe, with LPS derived from Salmonella enteritidis endotoxin (Lot 27H4127; $0.05 \mathrm{mg} / \mathrm{kg}$ in $<0.1 \mathrm{~mL}$; Sigma Chemical Co., Sydney, Australia) dissolved in PBS or the equivalent volume of the vehicle (PBS). The dose of LPS used has previously been shown to activate the acute-phase response, but not cause mortality (7). LPS was reconstituted with sterile, pyrogen-free, PBS each day before injections. All injections were given at $1000 \mathrm{~h}$. Untreated (i.e. no injection) control animals were not used in this study given that previous studies have demonstrated that these animals do not differ from saline-treated animals on any measure of HPA activity $(7,24)$.

Tumor cell maintenance. The MADB106 tumor cell is a selected variant cell line, obtained from a chemically induced pulmonary metastasis of a mammary adenocarcinoma, and is syngeneic to the F344 rat (18). The tumor cells were maintained in $5 \% \mathrm{CO}_{2}$ at $37^{\circ} \mathrm{C}$ in monolayer cultures, and were grown in complete media [RPMI 1640 media, GIBCO, Sydney, Australia, supplemented with $10 \%$ heat-inactivated fetal bovine serum, L-glutamine $(2 \mathrm{mM})$, nonessential amino acid $(0.1 \mathrm{mM})$, sodium pyruvate $(1 \mathrm{mM})$, and gentamicin $(0.01$ $\mathrm{mg} / \mathrm{mL})]$. Before use cells were trypsinized $(0.25 \%)$ to remove them from the flask and resuspended in PBS.

Induction and assessment of tumor metastases. Experiment 1 assessed resistance to tumor cell colonization in endotoxinand saline-treated animals using the MADB106 tumor cell model. After i.v. administration, this tumor cell reliably metastasizes to the lungs, where it forms well-defined surface metastases by $3-4 \mathrm{wk}$ after inoculation $(19,22)$. At $80-90 \mathrm{~d}$ of age rats were lightly anesthetized with halothane, and MADB106 tumor cells $\left(1 \times 10^{5}\right.$ cells in $0.5 \mathrm{~mL}$ of PBS $)$ were injected into the tail vein. The animals were returned to their cages and 3 wk later were euthanized with halothane; lungs were obtained for assessment of tumor metastasis. Lungs were removed and fixed for $24 \mathrm{~h}$ in Bouin's solution [72\% saturated picric acid solution, $23 \%$ formaldehyde $(37 \%), 5 \%$ glacial acetic acid (Sigma Chemical Co.-Aldrich, Sydney, Australia)]. The lungs were then transferred into ethanol (97\%). Surface metastases were counted by an independent observer, blind to group membership. The number of surface metastases indicates the number of tumor cells that are successful in evading detection by NK cells as they traffic to the lungs and is a reliable measure of tumor colonization (19).

Adult stress protocol. At the time of tumor inoculation animals were subjected to a period of restraint stress, a procedure known to reliably activate the HPA axis $(6,7,25,26)$. Rats in each neonatal condition were randomly allocated to one of two treatment conditions, "restraint" or "nonrestraint." Animals in the restraint condition were placed in a clear plastic restraint tube $(14 \times 7 \times 6 \mathrm{~cm})$ in their home cages for $10 \mathrm{~h}$ during the dark cycle (2000 h-0600 h) for $3 \mathrm{~d}$ before and after tumor inoculation. Rats in the nonrestraint condition were left undisturbed during this time, and had normal access to food and water. Animals in the restraint condition had no access to food and water during the period of restraint; hence, the effects of restraint can be attributed to the stress of food restriction in addition to restraint.

NK cytotoxicity assay. NK activity was assessed in experiment 2, using a standard chromium release assay. Endotoxinand saline-treated animals were randomly allocated to restraint or nonrestraint and underwent the restraint-stress procedure outlined above for $6 \mathrm{~d}(10 \mathrm{~h} / \mathrm{d})$. Immediately after completion of the last restraint session, animals were lightly anesthetized and blood was obtained via cardiac puncture. Animals in the nonrestraint groups were left unrestrained in their home cages during this time. Blood was obtained in the same manner and 
at the same time as for the animals in the restraint groups. Whole blood was used rather than separated leukocytes because this minimizes the time between blood collection and assessment of cytotoxicity. Previous studies have indicated that this method is comparable to methods using isolated leukocytes $(20,21,27)$. Blood was drawn into heparinized tubes. Exactly $1 \mathrm{~mL}$ of blood was washed once with PBS (diluted 1:4, centrifuged at $300 \times g$ for $10 \mathrm{~min}$, and supernatant aspirated to original volume) and twice with complete medium. YAC cells were used as the target cells, and were labeled by incubation with $200 \mu \mathrm{Ci}$ of ${ }^{51} \mathrm{Cr}$ for $1.5 \mathrm{~h}$ at $37^{\circ} \mathrm{C}$. They were then washed twice in complete medium and their concentration adjusted to the desired concentration. For each of the four E:T ratios used, $100 \mu \mathrm{L}$ of washed blood was placed into each well of a microtiter plate and $150 \mu \mathrm{L}$ of ${ }^{51} \mathrm{Cr}$-labeled YAC tumor cells in complete medium was placed on top of the blood. A concentration of $40 \times 10^{4} / \mathrm{mL}$ YAC cells was used as the lowest E:T ratio, and sequentially diluted by 2 to produce higher E:T ratios. Plates were centrifuged at $500 \times g$ for 10 min and then incubated for $4 \mathrm{~h}$ at $37^{\circ} \mathrm{C}$ in $5 \% \mathrm{CO}_{2}$. After this, plates were centrifuged again ( $10 \mathrm{~min}), 100-\mu \mathrm{L}$ aliquots of the supernatant were recovered from each well, and the amount of radioactivity was determined using a gamma counter. The spontaneous release (i.e. target without effector cells) and maximal release (i.e. target cells alone in medium containing $1 \%$ Triton X-100) of radioactivity from tumor cells was measured, and the percent specific lysis was calculated for each E:T ratio using the formula $\left[\left(0.8 \times\right.\right.$ experimental ${ }^{51} \mathrm{Cr}$ release - spontaneous ${ }^{51} \mathrm{Cr}$ release) / (maximum ${ }^{51} \mathrm{Cr}$ release spontaneous ${ }^{51} \mathrm{Cr}$ release) $] \times 100$. The experimental release is multiplied by 0.8 to correct for the reduction in supernatant volume, caused by the presence of red blood cells in all wells apart from those used to assess the maximum and spontaneous release.

Corticosterone assay. To test the reactivity of the HPA axis neonatal endotoxin- and saline-treated animals were placed in restraint tubes for $20 \mathrm{~min}$ with no access to food and water. Immediately after removal from restraint tubes, rats were lightly anesthetized with halothane and blood was obtained immediately via cardiac puncture into heparinized syringes. During the same period, animals in the nonrestraint groups were left unrestrained in their home cages with no access to food and water. Blood was obtained from nonrestraint animals in the same manner as for the animals in the restraint groups, immediately after removal from their home cages. Samples were obtained at $0800 \mathrm{~h}$ and were stored at $-80^{\circ} \mathrm{C}$ until assayed. Plasma corticosterone levels were assessed with a rat corticosterone ${ }^{125}$ I RIA kit (ICN Biomedicals Inc., Costa Mesa, CA, U.S.A.). The reported recovery of exogenous corticosterone is $100 \%$, and intra- and interassay coefficients of variation were $<10.3 \%$ and $<7.2 \%$, respectively.

Animal ethics. All procedures were approved by the Animal Ethics Committee of the University of Newcastle. In accordance with the guidelines of the committee, all procedures were conducted in such a manner as to minimize animal suffering, minimize the numbers of animals used, and to use in vitro methods when possible.
Statistical analysis. Data analysis was performed using the Statistical Package for the Social Sciences (SPSS, Inc., Chicago, IL, U.S.A.). Regression and trend analysis was performed on weight and NK data; all other data were analyzed using ANOVA. Multiple pairwise comparisons ( $t$ test) were performed using the Bonferroni adjustment for the $\alpha$ level. The $\alpha$ levels for each set of comparisons is $0.05 / \mathrm{k}=$ no. of comparisons.

\section{RESULTS}

Effect of neonatal endotoxin treatment on weight gain. Figure 1 illustrates the weights of male pups after the time at which they were separated from their siblings and housed individually. Endotoxin-treated males weigh less than salinetreated animals at all times from d 34 up to $d 74$. The magnitude of the difference between the two treatment conditions is relatively constant across d 36-74, the difference averaging $17.1 \mathrm{~g}$. Multivariate regression analysis revealed a significant relationship between "day" and "neonatal treatment" and weight $\left(F_{2,897}=350.86, p<0.05, r^{2}=88.6 \%\right)$. Both factors accounted for a significant proportion of the variance ( $p<0.05$ in both cases). The weight of animals in the endotoxin group was significantly lower than that of animals in the saline group at all times ( $p<0.05$ in all cases).

Effect of neonatal endotoxin treatment on tumor resistance in adulthood. Figure 2 illustrates the number of lung metastases for each experimental group after restraint or nonrestraint. A two-way ANOVA, drug (2) by restraint (2), on the number of metastases revealed a significant effect of restraint $\left(F_{1,23}=\right.$ $17.21, p<0.001)$ and drug $\left(F_{1,23}=16.65, p<0.001\right)$. The mean number of tumors was significantly higher in restraint versus nonrestraint groups and in the endotoxin versus saline groups.

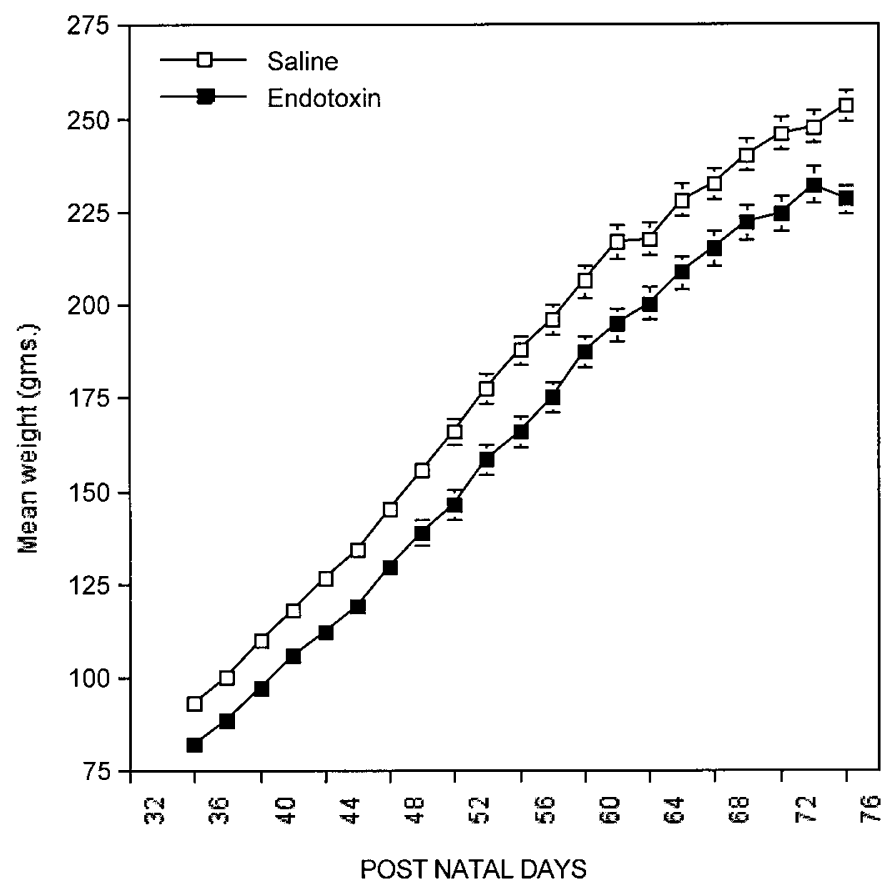

Figure 1. Mean ( \pm SEM) weights $(\mathrm{g})$ for males from the two treatment conditions; saline $(n=32)$ and endotoxin $(n=28)$ during postnatal d 36-74. 


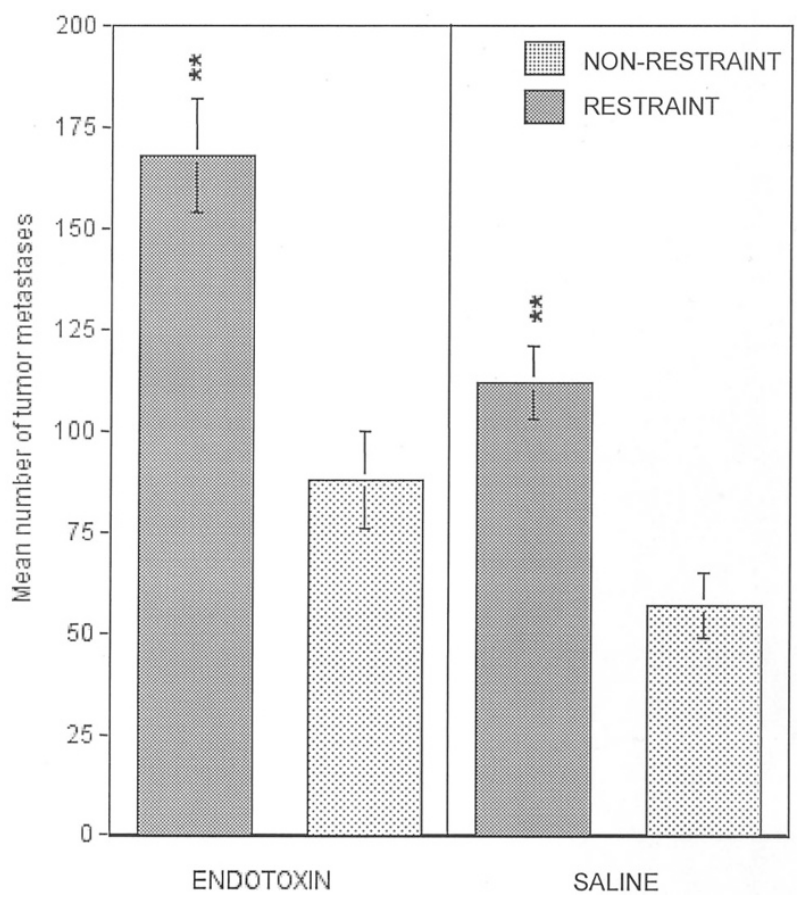

Figure 2. Mean ( \pm SEM) number of lung metastases for endotoxin versus saline groups across restraint versus nonrestraint groups ( $n=7$ /group). Significant contrasts between the restraint and nonrestraint groups are illustrated with asterisks, $* * p<0.01$.

Effect of neonatal endotoxin treatment on NK activity in adulthood. Figure 3 illustrates the effect of neonatal endotoxin versus saline treatment on $\mathrm{NK}$ activity in male rats subjected to

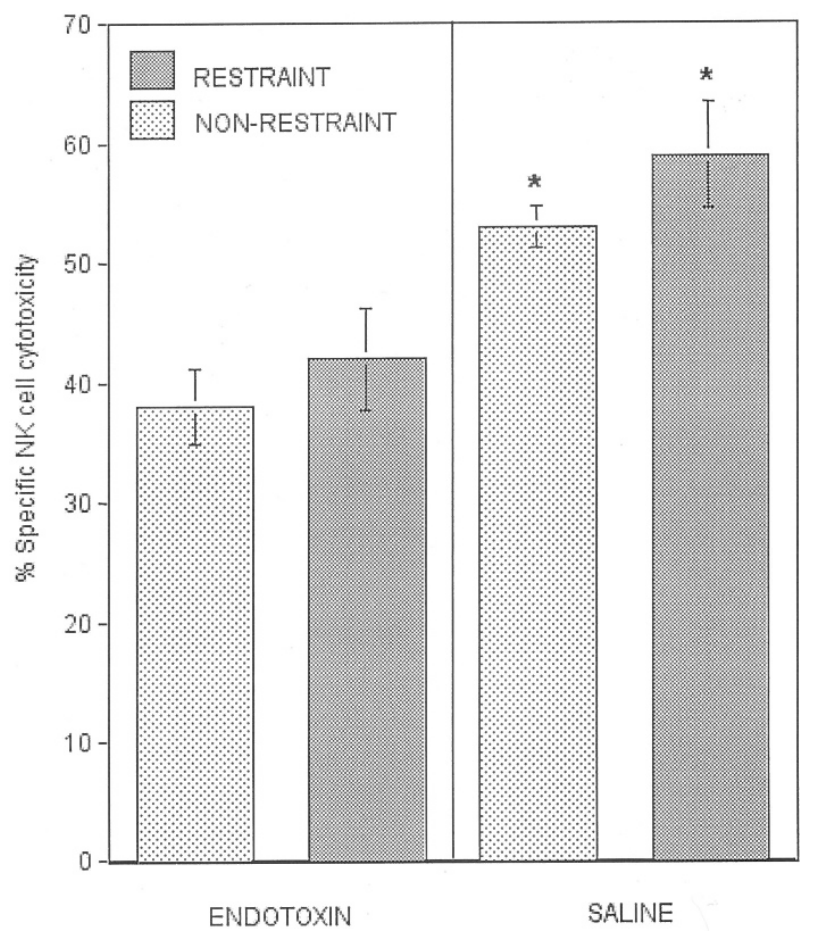

Figure 3. Mean ( \pm SEM) NK cell activity for endotoxin versus saline groups across restraint versus nonrestraint groups, E:T ratio 4:1 $(n=7$ /group). Significant contrasts between the endotoxin and saline groups are illustrated with asterisks, ${ }^{*} p<0.05$. restraint or nonrestraint conditions in adulthood. Trend analysis revealed a similar pattern across each of the four E:T ratios. Data analysis is reported on the highest ratio (E:T ratio 4:1). A two-way ANOVA, drug (2) by restraint (2), on NK activity revealed a significant effect for drug $\left(F_{1,23}=7.91, p<0.01\right)$. NK activity was significantly lower in the endotoxin- versus saline-treated animals.

Effect of neonatal endotoxin exposure on HPA reactivity in adulthood. Figure 4 illustrates the effect of neonatal endotoxin versus saline treatment on plasma corticosterone levels in rats subjected to acute restraint stress in adulthood. A two-way ANOVA, drug (2) by restraint (2), on corticosterone responses revealed a significant interaction between drug and restraint $\left(F_{1,23}=6.29, p<0.05\right)$. Both endotoxin- and saline-treated animals demonstrated significantly higher corticosterone levels in the restraint group compared with the nonrestraint group ( $p$ $<0.001$ in both cases). After restraint, corticosterone levels were significantly higher in endotoxin- versus saline-treated animals $(p<0.05)$. There were no significant differences between nonrestraint endotoxin and saline groups.

\section{DISCUSSION}

The findings of this study provide empirical evidence that early life exposure to bacterial stimuli can impair tumor immunity in adulthood. We report that exposure of rat pups to a bacterial endotoxin in the early postnatal period decreased resistance to tumor growth and depressed the activity of NK cells when these animals reached adulthood. This study also demonstrates that neonatal exposure to a bacterial endotoxin potentiated corticosterone responses to acute stress in adult-

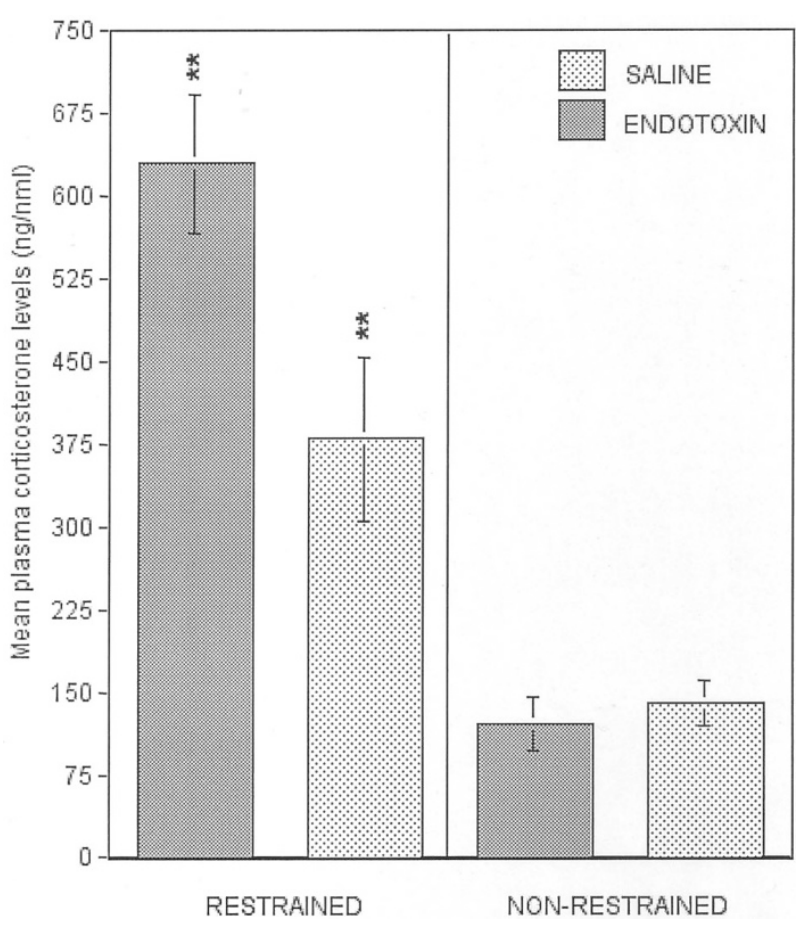

Figure 4. Mean ( \pm SEM) plasma level of corticosterone for endotoxin versus saline groups across restraint versus nonrestraint groups $(n=7$ /group). Significant contrasts between the endotoxin and saline groups are illustrated with asterisks, ${ }^{*} p<0.05$. 
hood. Finally, neonatal endotoxin exposure produced a marked decrement in weight gain that persisted into adulthood. The findings of this study are of possible clinical significance given that 1 ) neonatal exposure to infectious agents is a common risk for newborn infants; 2) one of the more common causes of infection in the neonate is Gram-negative bacteria (bacterial endotoxins are Gram-negative and, as such, are useful in modeling the effects of neonatal sepsis); and 3) the first $10 \mathrm{~d}$ of a rat's life are in some ways comparable to the last trimester of a human pregnancy. The long-term effects we report in the rat may, therefore, generalize to the effects of in utero bacterial exposure in the human fetus.

The primary finding of this study is that neonatal endotoxin was found to impair a specific aspect of tumor resistance in the adult rat. It has previously been demonstrated that exposure to stress potentiates colonization of the MADB106 tumor cell $(20,21)$. Given that bacterial endotoxin is associated with a hyperresponsivity to stress in adulthood, it was hypothesized that this may result in a potentiation of the effect of stress on tumor colonization. Consistent with this proposal, all animals subjected to restraint stress developed significantly more tumors than did unrestrained animals, and this effect was significantly greater in animals exposed to bacterial endotoxin as neonates. It is significant to note that the tumorigenic effect of endotoxin exposure was also evident in animals not subjected to restraint stress in adulthood.

Colonization of the lungs by the MADB106 tumor cell has previously been shown to be tightly regulated by the activity of NK cells, the immune cell population critically involved in the surveillance and eradication of tumor and virus-infected cells $(18,19)$. For this reason the MADB106 tumor cell model is typically referred to as an in vivo model of NK activity, NK cell activity being predictive of tumor colonization. In line with the predictions of this model, the present study demonstrates that NK cell activity was significantly lower in endotoxintreated animals compared with saline-treated animals. Acrossgroup correlations on NK activity did not accurately reflect group differences in tumor colonization. However, this is not inconsistent with predications of the model, as NK activity is only predictive of tumor outcome when measured within the first $24 \mathrm{~h}$ after tumor inoculation (19). NK activity in this study was assessed at the end of the restraint period, $3 \mathrm{~d}$ after inoculation. At this time, regulation of tumor colonization is most likely via interaction with T-cell-mediated mechanisms (26). The NK cell is critical in determining whether antigenstimulated $\mathrm{CD}^{+}$cells proliferate or differentiate into active cytotoxic $\mathrm{T}$ lymphocytes (28), and there is recent evidence to suggest that T-cell mechanisms play a role in regulation of MADB106 metastasis in the later postinoculation stages (28). Thus, impaired surveillance by NK cells may be one mechanism to account for the increased incidence of tumors in endotoxin-treated animals; however, it is also likely that other immunologic mechanisms may well be affected by neonatal endotoxin exposure and may account for the impaired tumor resistance.

The present study also demonstrates that endotoxin-treated neonates hypersecrete corticosterone when subjected to acute stress in adulthood. This hypersecretion is consistent with previous research demonstrating that endotoxin-treated neonates demonstrate altered stress-induced but not basal levels of corticosterone in adulthood (7). This outcome is attributed to a decrease in glucocorticoid receptor binding and density in regions involved in the inhibition of HPA activity. The decrease in receptor sites, and as such sensitivity, results in decreased tonic inhibition of glucocorticoid negative feedback, resulting in more-pronounced and longer-lasting corticosterone responses to stress (7). It is, however, important to note that the plasma concentrations of corticosterone reported in the present study may not necessarily reflect secretion rates but, rather, may reflect alterations in the level of CBG. The present study cannot address this issue as it did not assess CBG levels; however, Shanks et al. (7) have previously shown that endotoxin treatment does not significantly alter plasma CBG levels, suggesting that plasma levels are most likely reflective of differences in secretion rate. This hypersecretion of corticosterone may, in part, account for the impaired tumor immunity observed in endotoxin-treated animals because glucocorticoids are well documented to suppress the activity of NK cells (17). In this study, animals that were exposed to bacterial endotoxin as neonates and then subsequently exposed to stress in adulthood demonstrate a pattern of findings consistent with this hypothesis. The study does not, however, provide direct evidence of a causal relationship.

Finally, the present study also demonstrates that neonatal endotoxin was associated with a failure to gain weight. Neonatal endotoxin treatment has previously been shown to be associated with a decrease in weight gain (5). The present study demonstrates that this reduction in weight gain persists into adulthood. The mechanism through which endotoxin induces this long-term weight retardation is not clear. However, the observed differences are unlikely to be a result of endotoxin-induced anorexia. Previous studies have shown that weight reductions after twice daily endotoxin administration during the course of $4 \mathrm{~d}$ was paralleled by a significant decrement in food intake but only on the first day after treatment. After the first day of treatment, food consumption, but not weight gain, returned to preinjection levels, thus implicating a mechanism other than reduced caloric intake (29). An alternative explanation for the lower weight of endotoxin-treated animals is that the role of corticosterone in feeding behavior may have been disrupted as a result of neonatal exposure to endotoxin. Corticosterone plays a major role in the regulation of feeding behavior (30-32), and given the documented ability of endotoxin to dysregulate normal corticosterone secretion (7-9), it is possible that the weight differences may result from an increase in corticosterone levels in endotoxin-treated animals to a point at which they exert growth suppressive effects. Although the present study did not observe changes in basal corticosterone levels, Shanks et al. (9) has demonstrated that neonatal endotoxin-treated animals show marked differences in their diurnal pattern of corticosterone secretion, with increased pulses and greater pulse amplitudes. The present study only reports corticosterone levels at one time; clearly, attempts to understand the putative role of corticosterone in the effects reported in this study will require multiple measurement points. 
In conclusion, the present study demonstrates that neonatal endotoxin exposure is associated with long-term weight retardation, suppression of NK activity, and enhanced tumor metastasis in adulthood. In line with previous research we also report that neonatal exposure to endotoxin is associated with hypersecretion of corticosterone in response to acute stress in adulthood. The present study does not provide direct evidence to suggest that these elevated corticosterone levels account for the suppression of tumor immunity. This is, however, an avenue for future research. The findings of this study may have relevance for the human fetus given that the neonatal period in the rat is comparable, in some ways, to the last trimester of a human pregnancy. Research has recently demonstrated that alterations in the in utero environment have clear long-term health implications for the fetus, which include an increased risk of type 2 diabetes and cardiovascular disease in adulthood (33); the possibility that this may also affect cancer susceptibility is of potential significance.

Acknowledgments. The authors thank the expert technical assistance of Elly Huber and Mike Newton and the guidance and support of Professor Roger Smith.

\section{REFERENCES}

1. Akana SF, Cascio CS, Shinsako J, Dallman MF 1985 Corticosterone: narrow range required for normal body and thymus weight and ACTH. Am J Physiol 249:R527R532

2. Pierpaoli W, Kopp HG, Muller J, Keller M 1997 Interdependence between neuroendocrine programming and the generation of immune recognition in ontogeny. Cell Immunol 29:16-27

3. O'Grady MP, Hall NRS 1991 Long-term effects of neuroendocrine-immune interactions during early development. In: Ader R, Felton DL, Cohen N (eds) Psychoneuroimmunology, 2nd Ed. Academic Press, San Diego, pp 561-572

4. Reul JM, Stec I, Weigers GJ, Labeur MS, Linthorst AC, Arzt E, Holsboer F 1994 Prenatal immune challenge alters the hypothalamic-pituitary-adrenocortical axis in adult rats. J Clin Invest 93:2600-2607

5. Granger DA, Hood KE, Ikeda SC, Reed CL, Block ML 1996 Neonatal endotoxin exposure alters the development of social behaviour and the hypothalamic pituitary adrenal axis in selectively bred mice. Brain Behav Immun 10:249-259

6. Plotsky PM, Meaney MJ 1993 Early postnatal experience alters hypothalamic corticotropin-releasing factor (CRF) mRNA, median eminence CRF content and stressinduced release in adult rats. Mol Brain Res 18:195-200

7. Shanks N, Larocque S, Meaney MJ 1995 Neonatal endotoxin exposure alters the development of the hypothalamic-pituitary-adrenal axis: early illness and later responsivity to stress. J Neurosci 15:376-384

8. Shanks N, Meaney MJ 1994 Hypothalamic pituitary adrenal activation following endotoxin administration in the developing rat: a CRH-mediated effect. J Neuroendocrinol 6:375-383

9. Shanks N, Windle RJ, Perks PA, Harbuz MS, Jessop DS, Ingram CD, Lightman SL 2000 Early-life exposure to endotoxin alters hypothalamic-pituitary-adrenal function and predisposition to inflammation. Proc Natl Acad Sci USA 97:5645-5650

10. Liu D, Diorio J, Tannenbaum B, Caldji C, Francis D, Freedman A, Sharma S, Pearson D, Plotsky PM, Meaney MJ 1997 Maternal care, hippocampal glucocorticoid receptors, and hypothalamic-pituitary-adrenal responses to stress. Science 277:1659-1662
11. Meaney MJ, Diorio J, Francis D, Widdowson J, LaPlante P, Caldji C, Sharma S, Seckl JR, Plotsky PM 1996 Early environmental regulation of forebrain glucocorticoid receptor gene expression: implications for adrenocortical responses to stress. Dev Neurosci 18:49-72

12. Stanton ME, Gutierrez YR, Levine S 1988 Maternal deprivation potentiates pituitary adrenal stress response in infant rats. Behav Neurosci 102:692-700

13. Suchecki D, Mozaffarian D, Gross G, Rosenfeld P, Levine S 1993 Effects of maternal deprivation on the ACTH stress response in the infant rat. Neuroendocrinology 57:204-212

14. Witek-Janusek L 1988 Pituitary-adrenal response to bacteria in developing rats. Am J Physiol 255:E525-E530

15. Munck A, Guyre PM, Holbrook NJ 1984 Physiological functions of glucocorticoids in stress and their relation to pharmacological actions. Endocr Rev 5:25-44

16. Dhabhar FS, Miller AH, McEwen BS, Spencer RL 1995 Effects of stress on immune cell distribution: dynamic and hormonal mechanisms. J Immunol 154:5511-5527

17. Buckingham JC, Christian HC, Gillies GE, James GP 1996 The hypothalamopituitary-adrenocortical immune axis. In: Marsh JA, Kendall MD (eds) The Physiology of Immunity. CRC Press, Boca Raton, FL, pp 331-355

18. Barlozzari T, Leonhardt J, Wiltrout RH, Herberman RB, Reynolds CW 1985 Direct evidence for the role of LGL in the inhibition of experimental tumor metastases. J Immunol 134:2783-2789

19. Ben-Eliyahu S, Page GG 1992 In vivo assessment of natural killer cell activity in rats. Prog Neuroendocrinol 5:199-214

20. Ben-Eliyahu S 1998 Stress, natural killer cell activity and tumor metastasis: the role of catecholamines and corticosteroids. In: Levi A, Grauer E, Ben-Nathan D, De-Kloet ER (eds) The New Frontiers in Stress Research: Modulation of Brain Function. Harwood Academic Publishers, Amsterdam, pp 203-215

21. Ben-Eliyahu S, Page GG, Yirmiya R, Shakhar G 1999 Evidence that stress and surgical interventions promote tumor development by suppressing natural killer cell activity. Int J Cancer 80:880-888

22. Hodgson DM, Taylor AN, Chiappelli F, Kung M, Morrow NS 1996 Impact of acute food restriction on the colonization of MADB106 tumor cells to the lungs of Fischer 344 rats. Neuroimmunomodulation 3:371-381

23. Ben-Eliyahu S, Page GG, Shakhar G, Taylor AN 1996 Increased susceptibility to metastasis during pro-oestrus/oestrus in rats: possible role of oestradiol and natural killer cells. Br J Cancer 74:1900-1907

24. Meaney MJ Aitken DH, Sapolsky RM 1987 Thyroid hormones influence the development of hippocampal glucocorticoid receptors in the rat: a mechanism for the effects of postnatal handling on the development of the adrenocortical stress response. Neuroendocrinology 45:278-283

25. Ogawa T, Mikuni M, Kuroda Y, Muneoka K, Mori K, Takahashi K 1994 Periodic maternal deprivation alters stress response in adult offspring: potentiates the negative feedback regulation of restraint stress-induced adrenocortical response and reduces the frequencies of open field-induced behaviors. Pharmacol Biochem Behav 49:961967

26. Viau V, Sharma S, Plotsky PM, Meaney MJ 1993 Increased plasma ACTH responses to stress in nonhandled compared with handled rats require basal levels of corticosterone and are associated with increased levels of ACTH secretagogues in the median eminence. J Neurosci 13:1097-1105

27. Shakhar G, Ben-Eliyahu S 1998 In vivo beta-adrenergic stimulation suppresses natural killer activity and compromises resistance to tumor metastasis in rats. J Immunol 160:3251-3258

28. Ferdynand JK, Engelman EG 1996 Immune regulation: a critical link between NK cells and CTLs. Immunol Today 17:174-176

29. Peisen JN, McDonnell KV, Mulroney SE, Lumpkin MD 1995 Endotoxin-induced suppression of the somatotropic axis is mediated by interleukin-1 (beta) and corticotropin releasing factor in the juvenile rat. Comp Biochem Physiol C Pharmacol Toxicol 136:3378-3389

30. Kumar BA, Leibowitz SF 1988 Impact of acute corticosterone administration on feeding and macronutrient self selection patterns. Am J Physiol 254:R222-R228

31. Kumar BA, Papamichael M, Leibowitz SF 1988 Feeding and macronutrient selection patterns in rats: adrenalectomy and chronic corticosterone replacement. Physiol Behav 42:581-589

32. Devenport L, Thomas T, Knehans A, Sundstrom A 1990 Acute, chronic, and interactive effects of type I and II corticosterone receptor stimulation of feeding and weight gain. Physiol Behav 47:1221-1228

33. Barker DJP 1999 The fetal origins of type 2 diabetes mellitus. Ann Intern Med 130:322-324 